ENDODONTICS; CARDIOLOGY

\section{Endodontic variables and coronary heart disease}

Frisk $F_{1}$ Hakeberg M et al. Acta Odontol Scand 2003; 61: 257-262

No association was found.

In an initial cohort of 1622 women randomly selected in Gothenburg in 1968 for examination every 12 years in a longitudinal medical and dental investigation, 90\% took part; some were lost and younger groups were added as time passed. The present study used data from a survey in 1992-3.

In 1056 patients, 106 were diagnosed with coronary heart disease (CHD). There were significant differences between CHD and other patients in respect of mean number of teeth (13 v. 18), age (72 v. 65), hypertension, serum factors, obesity markers, smoking and life satisfaction. There were no differences in the mean numbers of teeth with root fillings (3.0 v. 3.4), or with periapical disease $(0.5 \mathrm{v} .0 .4)$. When a multivariate logistic regression model was developed, only tooth loss and age gave significant odds ratios: respectively, 2.7 and 1.07 .

The authors discuss factors which might explain their findings, including the possible effects of diet as a common factor in CHD and tooth loss.

doi:10.1038/sj.bdj.4811076

\section{ENDODONTICS}

\section{Long-term survival of root-canal-treated teeth: a retrospective study over 10 years}

Dammaschke T, Steven D et al. J Endodon 2003; 29: 638-643

The 10 year survival rate for root fillings placed by students was $85 \%$.

Conventional biomechanical root canal treatment was performed by dental students for 190 teeth in 144 patients, aged 18-74 yrs during 1987-8. A requirement for inclusion in this study was a minimum of 10 yrs' follow-up. Half the teeth had one canal, 1/5 had 2, 1/4 had 3 and the remainder had 4 canals treated. About $1 / 4$ had apical lesions. Two fifths of the teeth were filled to within $1 \mathrm{~mm}$ of the apex, and another $2 / 5$ to within a further $1 \mathrm{~mm}, 1 / 10$ were more than $2 \mathrm{~mm}$ underfilled and $1 / 15$ were overfilled.

One tooth in 7 was extracted during the follow-up, and tooth retention was used as the success criterion. Survival was not affected significantly by patient age, gender, jaw, tooth type or the number of root canals in the tooth. However, a pre-existing apical lesion reduced the $11 \mathrm{yr}$ survival rate from $87 \%$ to $64 \%$. Sealing with phosphate or glass ionomer also reduced survival, as did underfilling by $2 \mathrm{~mm}$, or overfilling.

doi:10.1038/sj.bdj.4811077
ORAL PATHOLOGY

Oral pyogenic granuloma in Jordanians: a retrospective analysis of 108 cases

Al Khateeb T, Ababneh K J Oral Maxillofac Surg 2003; 61: 1285-1288

The recurrence rate was $6 \%$.

Over a period of 11 years, 108 patients (68 female) aged 3-85 yrs had pyogenic granulomata removed in a Jordanian university dental clinic. Pregnancy lesions were excluded. Most lesions were treated in the second to fourth decades of life. Nearly half of the lesions were on the gingiva, followed by the lower lip, tongue, buccal mucosa, upper lip and palate.

Treatment was by surgical excision, and histopathological findings were unremarkable in all cases. The authors noted that their results supported a traumatic aetiology for lesions not on the gingiva. During the 2-12 yr follow-up, 23 patients failed to return, but in those who did, there were 5 recurrences.

doi:10.1038/sj.bdj.4811078

\section{ENDODONTICS}

Treatment outcome in endodontics: the Toronto study. Phase 1: initial treatment

Friedman S, Abitbol S et al. J Endodon 2003; 29: 787-793

Teeth treated for apical periodontitis responded less satisfactorily.

Endodontic treatment was performed by supervised graduate students for 405 teeth in 350 patients. After 4-6 yrs, 109 patients with 128 teeth could not be contacted for follow-up; a further 136 teeth were not available because patients declined the invitation despite the offer of financial compensation for attendance, and a further 21 teeth had been extracted for various reasons. In respect of pre-operative apical radiolucency, the dropouts and responders did not differ significantly $(P>0.7)$.

In the remaining 120 teeth, of which 97 were healed without apical periodontitis, the potential prognostic factors examined were the number of roots, periapical radiolucency, pulp vitality, lateral or vertical condensation of gutta percha and the presence of a temporary or definitive seal. Stepwise logistic regression analysis showed that only the presence of a pre-existent radiolucency was likely to predict failure $(\mathrm{OR}=3.7)$. Significantly fewer multi-rooted than single-rooted teeth were healed when a radiolucency was present before treatment, though this factor did not predict the outcome.

doi:10.1038/sj.bdj.4811079 